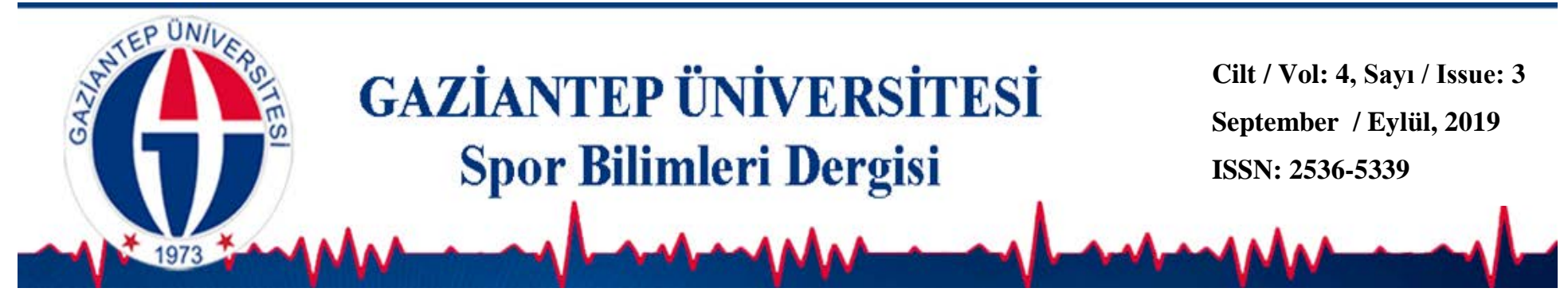

\title{
Farklı Yarışma Düzeylerindeki Kadın Voleybolcuların Fonksiyonel Hareket Taraması Test Skorlarının Karşılaştırılması
}

\author{
Emre ALTUNDAĞ ${ }^{1}$ (D) Hasan AKA ${ }^{2}$ (I) Serkan İBiş ${ }^{3}$ (i) \\ Cengiz AKARÇEŞME ${ }^{4}$ (D) Songül KURT $T^{5 *}$ \\ ${ }^{1}$ Gazi Üniversitesi, Sağlık Bilimleri Enstitüsü, ANKARA \\ ${ }^{2}$ Milli Eğitim Bakanlığ, ANKARA \\ ${ }^{3}$ Niğde Üniversitesi, Beden Eğitimi ve Spor Yüksekokulu, $N \dot{I G} D E$ \\ ${ }^{4}$ Gazi Üniversitesi, Spor Bilimleri Fakültesi, ANKARA \\ ${ }^{5}$ Niğde Ömer Halisdemir Üniversitesi, $N \dot{I} \breve{G} D E$
}

DOI: $10.31680 / g a u n j s s .584421$

Orijinal Makale / Original Article

Geliş Tarihi / Received: 29.06.2019 Kabul Tarihi / Accepted: 15.08.2019 Yayın Tarihi / Published: 22.09.2019

Öz

Bu çalışma farklı yarışma düzeylerindeki kadın voleybolcuların Fonksiyonel Hareket Taraması (FHT) test skorlarının karşılaştırııması amacıyla yapılmıştır. Çalışmaya midi $(n=11)$, küçük $(n=14)$, yıldız $(n=14)$ ve genç $(n=8)$ kategorilerinde voleybol oynayan toplam 47 gönüllü kadın sporcu katılmıştır. Katılımcıların fonksiyonel hareket kalıpları FHT test kiti ile belirlenmiştir. Farklı kategorideki voleybolcuların FHT skorlarının karşılaştırılmasında Kruskal-Wallis H Testi kullanılmıştır. Sporcuların FHT(Yüksek Adımlama) sağ bacak skorlarında küçük ve midi takımları arasında küçük takım lehine ve FHT (Tek Hamlede Çökme) skorlarında küçük ve yıldız takımları arasında küçük takım lehine anlamlı bir fark tespit edilmesine rağmen $(p<0.05)$ çalışmanın diğer değişkenlerinde istatistiksel olarak anlamlı bir fark bulunmamıştır. Ayrıca sporcularda yaralanma ihtimali ile ilgili bilgi veren FHT (Toplam Skorunun) her kategorideki sporcularda kritik sınır olarak belirtilen 14'ün üzerinde olduğu

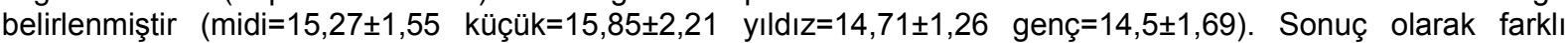
kategorideki voleybolcuların fonksiyonel hareket becerilerinin yarışma düzeyi ve yaşları ile ilgili olmadığı düşünülmektedir.

Anahtar Kelimeler: Voleybol, fonksiyonel hareket taraması, yarışma düzeyleri

\section{The Comparison of Functional Movement Screening Test Scores of Female}

\section{Volleyball Players at Different Competition Levels}

\begin{abstract}
This study was conducted to compare the Functional Movement Screening (FMS) test scores of female volleyball players at different competition levels. A total of 47 volunteer female athletes who played volleyball from the midi $(n=11)$, small $(n=14)$, star $(n=14)$ and young $(n=8)$ categories participated in the study. Functional movement patterns of the participants were determined by FMS test kit. Kruskal-Wallis $\mathrm{H}$ Test was used to compare FMS scores of volleyball players who were at different categories. Although there was a significant difference between the small and midi teams in the FMS (Hurdle-Step) right leg scores of the athletes and in favor of the small team between the small and star teams in the FMS (İline Lunge) subscale scores $(p<0.05)$, there was no statistically significant difference in the other variables of the study. In addition, the FMS (Total Score) which provides information on the probability of injury in athletes, was found to be over 14 , which is the critical limit for athletes in each category (midi $=15.27 \pm 1.55$ small $=15.85 \pm 2.21$ star $=14.71 \pm 126$ young =14.5 \pm 1.69 ). As a result, it is considered that functional movement skills of different categories of volleyball players are not related to competition level and age.
\end{abstract}

Keywords: Volleyball, Functional movement screening, Competition levels

\footnotetext{
* Sorumlu Yazar: Songül KURT
}

E-mail: snglkrt@outlook.com 


\section{Giriş}

Elit bir voleybol oyuncusu bir sezon boyunca çok sayıda antrenman yapmakta ve müsabakaya katımaktadır. Sporcular antrenman ve müsabaka sayısının fazla olmasının da etkisiyle çeşitli yaralanmalara maruz kalmaktadır. Voleybol branşı, sporcuların yaralanma olasılığı fazla olan bir spor branşıdır (Solgard ve ark., 1995). Voleybolda sporcular özellikle alt ekstremiteye yönelik yaralanmalar yaşamaktadır (Marwan ve ark., 2012). Özellikle küçük yaşlardaki sporcularda bu tür problemler sıkça görülmektedir. Tek taraflı yüklenmeler, tek eksenli çalışmalar, vücudun yalnız bazı bölgelerinin çalıştırılması (sadece üst ekstremite, sadece alt ekstremite, sadece sağ taraf vb.) durumundan dolayı sporcuların bedenlerinde oluşan kassal dengesizlikler sporcuların günlük yaşam kalitesini ve sportif performansını olumsuz yönde etkilemektedir. Hatta bazı durumlarda ciddi sakatlanmalar veya sporsal faaliyetlerin sona ermesi görülebilmektedir. Bu sebeple vücudun beceri düzeyini, spora uygunluğunu ve performansını değerlendirebilmek için bazı fiziksel uygunluk ve performans parametrelerini analiz etmek gerekmektedir. Yapılan bir araştırmaya göre voleybol oyuncularındaki temel fiziksel performans karakteristiklerinin; yaş, deneyim, alt ekstremite, omuz, kalça kas gücü ve dengesi olduğu bulunmuştur. Sporcuların gelişimlerini değerlendirebilmek için yaş, cinsiyet ve fiziksel performans verilerinin belirlenmesi gerekmektedir (Ergun ve Baltacı, 2007).

Yapılan bazı araştırmalarda sporcuların hareket kalitesi ve atletik performansları yaralanma riski ile (Mens ve ark., 1999, Kraemer ve ark., 2004), temel hareket kalıplarındaki bozukluklar ise sportif yaralanmalarla ilişkilendirilmiştir (Cholewicki, 2005; Kraemer ve ark., 2004). Cook ve ark (1988) tarafından geliştirilen Fonksiyonel Hareket Taraması (FHT) prosedürü, sporcuların temel hareket kalıplarının değerlendirilmesine olanak sağlamaktadır (Cook ve ark., 2006). FHT test bataryası fonksiyonel hareketlerin kalitesini değerlendirerek hareketlerdeki kısıtlılık ve asimetrilerin tespit edilmesinde kullanılan biyomekaniksel bir tarama ve değerlendirme yöntemidir (Chorba ve ark., 2010). Ayrıca FHT test bataryası, sporcularda kas kuvveti, esneklik, hareket açıklığı, koordinasyon, denge ve propriyosepsiyonu (Cook ve ark., 2010) değerlendirmenin yanı sıra sporculardaki ağrıyı da değerlendirmek için kullanılmaktadır (Narducci ve ark., 2011). FHT testi sayesinde temel hareketler analiz edilerek sporcularda var olan asimetri, mobilite ve 
Altundağ E, Aka H, İbiş S, Akarçeşme C, Kurt S., (2019). Farklı Yarışma Düzeylerindeki Kadın Voleybolcuların Fonksiyonel Hareket Taraması Test Skorlarının Karşılaştırılması. Gaziantep Üniversitesi Spor Bilimleri Dergisi, 4(3), 319329.

stabilite durumları gözlemlenebilmekte ve sporcunun yaralanma riskine dair tahmini bilgilere ulaşılmaktadır (Kiesel ve ark., 2007).

Sporculara uygulanacak bir test ile yaralanma riskine dair bilgiye ulaşılabilmesi antrenör ve sporcular için yaralanmaların önlenebilmesi adına hayati öneme sahip olabilir. Fonksiyonel hareket taraması ucuz, girişimsel olmayan ve temel fiziksel hareketlerin uygulanmasına (Perry ve Koehle, 2012) imkân veren güvenilir bir test bataryasıdır (Minick ve ark., 2010). FHT ile performans ölçüm laboratuarlarına ve pahalı ekipmanlara gerek duyulmadan saha içerisinde kolay bir şekilde ölçümlerin yapılmasıyla sporcuların gelişimlerinin daha sık aralıklarla takibinin yapılması sağlanabilir. Ayrıca FHT ile sporcularda tespit edilen eksiklikler, FHT'nin skorlanmasına göre hazırlanan ve istenilen antrenman metoduna göre uygulanabilen düzeltici egzersizlerle sporcuların hareketlerinde, fiziksel uygunluklarında ve performanslarında iyileşmeler sağlanabilmektedir. Literatür incelendiğinde FHT test bataryası kullanılarak yapılan araştırmaların daha çok yabancı literatürde olduğu görülürken, yerli literatürde sınırlı sayıda araştırma bulunmaktadır. Yapılan literatür incelemesine göre farklı yarışma kategorilerindeki (midi, küçük, yıldız, genç) kadın voleybolcuların FHT testine yönelik olarak yapılan bir araştırmaya rastlanılmamıştır. Bu da yapılan çalışmanın özgünlüğünü ifade ederken aynı zamanda literatüre katkı sağlayacağı düşünülmektedir. Bu bilgilerden hareketle bu çalışmadaki amacımız, farklı yarışma seviyelerindeki lisanslı kadın voleybolcuların fonksiyonel hareket kalıplarının karşılaştırılmasıdır.

\section{Yöntem}

\section{Evren ve Örneklem}

Çalışmaya Halkbankası kadın voleybol takımında midi $(n=11)$, küçük $(n=14)$, yıldız ( $n=14)$ ve genç $(n=8)$ kategorilerinde oynayan toplam 47 sporcu gönüllü olarak katılmıştır. Çalışmanın evrenini Halkbankası bayan voleybol takımı, örneklemini ise, Halkbankası bayan voleybol takımındaki midi, küçük, yıldız ve genç kategorilerindeki sporcular oluşturmaktadır.

\section{Verilerin Toplanması}

Sporculara bazı antropometrik ölçümler ile Fonksiyonel Hareket Tarama testi uygulanmıştır. Çalışmaya katılan sporculardan son 6 ay içerisinde herhangi bir sportif yaralanma geçirmeyenler araştırma grubuna dahil edilmiştir. Testler voleybolcuların 
Altundağ E, Aka H, İbiş S, Akarçeşme C, Kurt S., (2019). Farklı Yarışma Düzeylerindeki Kadın Voleybolcuların Fonksiyonel Hareket Taraması Test Skorlarının Karşılaştırılması. Gaziantep Üniversitesi Spor Bilimleri Dergisi, 4(3), 319329.

izin günlerinde uygulanmış ve sporculardan katılacakları testler öncesinde son 24 saat içerisinde herhangi bir sportif aktiviteye katılmamaları istenmiştir.

\section{Antropometrik Ölçümler}

Sporcuların boy ve vücut ağırlığı ölçümleri, boy ölçerli baskül kullanılarak çıplak ayakla, şort ve tişört giydirilerek belirlenmiştir.

\section{Fonksiyonel Hareket Tarama Testi}

$\mathrm{Bu}$ araştırma kapsamında sporcuların fonksiyonel hareketleri Gray Cook (1988) tarafından geliştirilen Fonksiyonel Hareket Tarama Test kiti kullanılarak belirlenmiştir (Güzel ve Kafa, 2017). Bu testte yer alan 7 temel hareket sırasıyla, Derin Çömelme (Deep Squat), Yüksek Admlama (Hurdle Step), Tek Çizgide Hamle (İn Line Lunge), Omuz Mobilitesi (Shoulder Mobility), Aktif Düz Bacak Kaldırma (Active Straight Leg Raise), Gövde Stabilite Şınavı (Trunk Stability Push Up), Rotasyon Stabilitesi (Rotary Stability)'dir. Katılımcı gruplara uygulanan FHT testi sertifikalı uzman tarafından yapılmıştır. Ölçümler, sporculara ısınma yaptırılmadan uygulanmıştır. Sporculara test öncesinde uzman tarafından test hakkında bilgilendirme yapılmış, hareketler detaylı olarak gösterilmiştir. Test sırasında her bir hareket üç kez tekrarlanmıştır. Katılımcılardan testin uygulanması esnasında oluşabilecek bir acı veya rahatsızlık durumunu belirtmeleri istenmiştir. Testte önce kendi içinde tek taraflı değerlendirilen hareketler (derin çökme, şınav testi) ölçülmüştür. İki taraflı ölçülen testlerde ise; (yüksek adımlama, tek hamlede çökme, omuz mobilitesi, aktif düz bacak kaldırma ve rotasyon gövdesi) sağ ve sol olmak üzere ayrı ayrı puanlama yapılmıştır. Puanlama esnasında katılımcıların her iki vücut yönünden aldığı skorlar kaydedilmiştir. Fakat hareketten aldığı en düşük puan testin sonucu olarak kabul edilmiştir. Örn; yüksek adımlamada (hurdle step) sol bacak puanı 1, sağ bacak puanı 2 alan sporcunun puanı 1 olarak kaydedilmiştir. Bu prosedür iki taraflı hareketler için uygulanmıştır (Cook ve ark., 2010). Fonksiyonel hareket taramasının puanlamasında her teste kendi içerisinde puan verilir ve FHT skoru uygulanan yedi testin toplamıdır. FHT hareket formlarını test ederken 7, ağrıyı tanımlamak için de 3 test kullanılmaktadır (Kiesel ve ark., 2007). Testte her bir harekete 0-3 arasında puan verilir, testten alınabilecek en yüksek puan 21, en düşük puan 0'dır (Cook ve ark., 2006). FHT toplam skoru 14 puandan düşük olan bireylerin 14 puandan daha yüksek olan bireylere göre yaralanma riskleri daha fazladır (Kiesel ve ark, 2007). 


\section{Verilerin analizi}

Elde edilen verilerin istatistiksel olarak analiz edilmesinde SPSS 22,0 paket programı kullanılmıştır. Verilerin normal dağılıma uyup uymadıklarını belirlemek için normallik testi uygulanmıştır. Araştırmaya midi $(n=11)$, küçük $(n=14)$, yıldız $(n=14)$, genç $(n=8)$ olmak üzere toplamda 47 kişi gönüllü olarak katılmıştır. Elde edilen verilerin normallik dağılımı Shapiro-Wilks testi ile belirlenmiştir. Veriler normal dağılım göstermediğinden çoklu karşılaştırmalar için nonparametrik testlerden Kruskal-Wallis H Testi uygulanmıştır. Çalışmada anlamlılık düzeyi $p<0.05$ olarak kabul edilmiştir.

\section{Bulgular}

Tablo 1. Voleybolcuların fiziksel özellikleri

\begin{tabular}{lcccc}
\hline Gruplar & $\mathbf{N}$ & Yaş & Boy & Kilo \\
\hline & & $\overline{\mathrm{x}} \pm \mathrm{S}$ & $\overline{\mathrm{x}} \pm \mathrm{S}$ & $\overline{\mathrm{x}} \pm \mathrm{S}$ \\
\hline Genç & 8 & $19,12 \pm, 35$ & $180,12 \pm 9,80$ & $64,75 \pm 6,31$ \\
\hline Yıldız & 14 & $17,50 \pm, 51$ & $180,00 \pm 7,35$ & $81,00 \pm 66,21$ \\
\hline Küçük & 14 & $15,92 \pm, 26$ & $172,85 \pm 4,46$ & $59,14 \pm 5,62$ \\
\hline Midi & 11 & $13,63 \pm 1,20$ & $166,72 \pm 4,88$ & $57,09 \pm 2,77$ \\
\hline
\end{tabular}

Tablo 1 incelendiğinde, genç kategorisindeki katılımcıların yaş ortalaması $19,12 \pm, 35$, boy uzunluklarının ortalaması 180,12 $\pm 9,80$, vücut ağırlıklarının ortalaması ise $64,75 \pm 6,31$ olarak belirlenmiştir. Yıldız kategorisindeki katılımcıların yaş

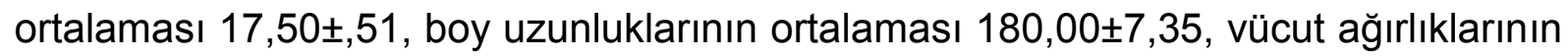
ortalaması ise $81,00 \pm 66,21$ olarak belirlenmiştir. Küçük kategorisindeki katılımcıların fiziksel özelliklerinde yaş ortalaması $15,92 \pm, 26$, boy uzunluklarının ortalaması $172,85 \pm 4,46$, vücut ağılıklarının ortalaması ise $59,14 \pm 5,62$ olarak belirlenmiştir. Midi kategorisindeki katılımcıların ise yaş ortalaması $13,63 \pm 1,20$, boy uzunluklarının ortalaması $166,72 \pm 4,88$, vücut ağırlıklarının ortalaması ise $57,09 \pm 2,77$ olarak belirlenmiştir.

Tablo 2. Voleybolcuların oynadıkları kategorilere göre FHT skorlarının karşılaştırılması

\begin{tabular}{|c|c|c|c|c|c|c|c|}
\hline Değişken & Grup & $\bar{x} \pm \mathrm{sd}$ & $\mathbf{N}$ & Sira Ort. & $x^{2}$ & p & $\begin{array}{l}\text { Çoklu } \\
\text { Kars. }\end{array}$ \\
\hline \multirow{4}{*}{$\begin{array}{c}\text { FHT } \\
\text { (Derin } \\
\text { Çömelme) }\end{array}$} & Yıldız & $1,85 \pm, 53$ & 14 & 20,5 & \multirow{4}{*}{7,43} & \multirow{4}{*}{0,06} & \\
\hline & Genç & $2,00 \pm, 75$ & 8 & 22,63 & & & \\
\hline & Küçük & $2,30 \pm, 48$ & 14 & 29,86 & & & \\
\hline & Midi & $2,00 \pm, 00$ & 11 & 22 & & & \\
\hline FHT & Yıldız & $2,21 \pm, 42$ & 14 & 24,04 & \multirow{4}{*}{0,13} & \multirow{4}{*}{0,99} & \\
\hline (Yüksek & Genç & $2,25 \pm, 46$ & 8 & 24,88 & & & \\
\hline Adımlama) & Küçük & $2,23 \pm, 43$ & 14 & 24,04 & & & \\
\hline sol & Midi & $2,18 \pm, 40$ & 11 & 23,27 & & & \\
\hline FHT & Yıldız & $2,21 \pm, 42$ & 14 & 22,04 & 7,65 & $0,05^{\star}$ & K-M \\
\hline
\end{tabular}


Altundağ E, Aka H, İbiş S, Akarçeşme C, Kurt S., (2019). Farklı Yarışma Düzeylerindeki Kadın Voleybolcuların Fonksiyonel Hareket Taraması Test Skorlarının Karşılaştırılması. Gaziantep Üniversitesi Spor Bilimleri Dergisi, 4(3), 319329.

\begin{tabular}{|c|c|c|c|c|c|c|c|}
\hline (Yüksek & Genç & $2,25 \pm, 46$ & 8 & 22,88 & & & \\
\hline Adımlama) & Küçük & $2,53 \pm, 51$ & 14 & 30,43 & & & \\
\hline Sağ & Midi & $2,09 \pm, 30$ & 11 & 19,14 & & & \\
\hline FHT & Yıldız & $2,14 \pm, 36$ & 14 & 23,86 & \multirow{4}{*}{0,79} & \multirow{4}{*}{0,85} & \\
\hline (Yüksek & Genç & $2,12 \pm, 35$ & 8 & 23,44 & & & \\
\hline Adımlama) & Küçük & $2,23 \pm, 43$ & 14 & 25,54 & & & \\
\hline Toplam & Midi & $2,09 \pm, 30$ & 11 & 22,64 & & & \\
\hline $\mathrm{FHT}$ & Yıldız & $2,21 \pm, 42$ & 14 & 23,43 & \multirow{4}{*}{3,77} & \multirow{4}{*}{0,29} & \\
\hline (Tek & Genç & $2,12 \pm, 64$ & 8 & 22,06 & & & \\
\hline Çizgide & Küçük & $2,38 \pm, 50$ & 14 & 28,36 & & & \\
\hline $\begin{array}{c}\text { Hamle) } \\
\text { Sol }\end{array}$ & Midi & $2,09 \pm, 30$ & 11 & 20,59 & & & \\
\hline $\mathrm{FHT}$ & Yıldız & $2,07 \pm, 26$ & 14 & 21,61 & \multirow{4}{*}{6} & \multirow{4}{*}{0,11} & \\
\hline (Tek & Genç & $2,00 \pm, 53$ & 8 & 20,5 & & & \\
\hline Çizgide & Küçük & $2,38 \pm, 50$ & 14 & 29,64 & & & \\
\hline $\begin{array}{c}\text { Hamle) } \\
\text { Sağ }\end{array}$ & Midi & $2,09 \pm, 53$ & 11 & 22,41 & & & \\
\hline FHT & Yıldız & $2,00 \pm, 00$ & 14 & 21 & \multirow{4}{*}{9,23} & \multirow{4}{*}{$0,03^{*}$} & \multirow{4}{*}{$\mathrm{K}-\mathrm{Y}$} \\
\hline (Tek & Genç & $2,00 \pm, 53$ & 8 & 21,38 & & & \\
\hline Çizgide & Küçük & $2,38 \pm, 50$ & 14 & 30,64 & & & \\
\hline $\begin{array}{l}\text { Hamle) } \\
\text { Toplam }\end{array}$ & Midi & $2,00 \pm, 44$ & 11 & 21,27 & & & \\
\hline $\mathrm{FHT}$ & Yıldız & $2,35 \pm, 74$ & 14 & 23,61 & \multirow{4}{*}{1,59} & \multirow{4}{*}{0,66} & \\
\hline (Omuz & Genç & $2,12 \pm, 83$ & 8 & 19,81 & & & \\
\hline Mobilitesi) & Küçük & $2,38 \pm, 65$ & 14 & 24,43 & & & \\
\hline Sol & Midi & $2,54 \pm, 68$ & 11 & 27 & & & \\
\hline FHT & Yıldız & $2,50 \pm, 65$ & 14 & 21,75 & \multirow{4}{*}{3,2} & \multirow{4}{*}{0,36} & \\
\hline (Omuz & Genç & $2,37 \pm, 91$ & 8 & 21,56 & & & \\
\hline Mobilitesi) & Küçük & $2,84 \pm, 37$ & 14 & 28,43 & & & \\
\hline Sağ & Midi & $2,54 \pm, 68$ & 11 & 23 & & & \\
\hline FHT & Yıldız & 0 & 14 & 22,5 & \multirow{4}{*}{3,59} & \multirow{4}{*}{0,31} & \\
\hline (Omuz & Genç & 0 & 8 & 25,44 & & & \\
\hline Kontrol & Küçük & 0 & 14 & 25,86 & & & \\
\hline Testi) & Midi & 0 & 11 & 22,5 & & & \\
\hline $\mathrm{FHT}$ & Yıldız &, $00 \pm, 00$ & 14 & 25,75 & \multirow{4}{*}{4,6} & \multirow{4}{*}{0,2} & \\
\hline (Omuz & Genç & ,12士,35 & 8 & 16,75 & & & \\
\hline Mobilitesi) & Küçük &, $15 \pm, 37$ & 14 & 22,61 & & & \\
\hline Toplam & Midi &, $00 \pm, 00$ & 11 & 28,82 & & & \\
\hline FHT & Yıldız & $2,35 \pm, 74$ & 14 & 20,43 & \multirow{4}{*}{2,73} & \multirow{4}{*}{0,44} & \\
\hline (Aktif Düz & Genç & $1,62 \pm 1,06$ & 8 & 23,63 & & & \\
\hline Bacak & Küçük & $1,92 \pm 1,18$ & 14 & 24,5 & & & \\
\hline $\begin{array}{c}\text { Kaldırma) } \\
\text { Sol }\end{array}$ & Midi & $2,54 \pm, 68$ & 11 & 28,18 & & & \\
\hline $\mathrm{FHT}$ & Yıldız & $2,42 \pm, 51$ & 14 & 20,89 & & & \\
\hline (Aktif Düz & Genç & $2,50 \pm, 75$ & 8 & 22,25 & & & \\
\hline Bacak & Küçük & $2,53 \pm, 66$ & 14 & 23,86 & 3,46 & 0,33 & \\
\hline $\begin{array}{c}\text { Kaldırma) } \\
\text { Sağ }\end{array}$ & Midi & $2,72 \pm, 64$ & 11 & 29,41 & & & \\
\hline $\mathrm{FHT}$ & Yıldız & $2,35 \pm, 74$ & 14 & 19,5 & & & \\
\hline (Aktif Düz & Genç & $2,50 \pm, 53$ & 8 & 22,69 & & & \\
\hline Bacak & Küçük & $2,53 \pm, 51$ & 14 & 24,75 & 4,48 & 0,21 & \\
\hline $\begin{array}{l}\text { Kaldırma) } \\
\text { Toplam }\end{array}$ & Midi & $2,81 \pm, 40$ & 11 & 29,73 & & & \\
\hline FHT & Yıldız & $2,21 \pm, 69$ & 14 & 21,07 & & & \\
\hline (Gövde & Genç & $2,37 \pm, 74$ & 8 & 29,44 & 316 & 037 & \\
\hline Stabilite & Küçük & $2,46 \pm, 66$ & 14 & 25,68 & $3, \perp 6$ & U,3 & \\
\hline Şınavı) & Midi & $2,72 \pm, 64$ & 11 & 21,64 & & & \\
\hline $\mathrm{FHT}$ & Yıldız & $2,14 \pm, 36$ & 14 & 22,5 & 3,84 & 0,28 & \\
\hline
\end{tabular}


Altundağ E, Aka H, İbiş S, Akarçeşme C, Kurt S., (2019). Farklı Yarışma Düzeylerindeki Kadın Voleybolcuların Fonksiyonel Hareket Taraması Test Skorlarının Karşılaştırılması. Gaziantep Üniversitesi Spor Bilimleri Dergisi, 4(3), 319329.

\begin{tabular}{|c|c|c|c|c|c|c|}
\hline $\begin{array}{c}\text { (Uzatma } \\
\text { Kontrol } \\
\text { Testi) }\end{array}$ & $\begin{array}{c}\text { Genç } \\
\text { Küçük } \\
\text { Midi }\end{array}$ & $\begin{array}{c}2,37 \pm 1,06 \\
2,30 \pm, 48 \\
1,90 \pm 1,13\end{array}$ & $\begin{array}{c}8 \\
14 \\
11 \\
\end{array}$ & $\begin{array}{c}22,5 \\
24,25 \\
26,68 \\
\end{array}$ & & \\
\hline $\mathrm{FHT}$ & Yıldız &, $00 \pm, 00$ & 14 & 24 & \multirow[b]{2}{*}{0} & \multirow[b]{2}{*}{1} \\
\hline $\begin{array}{c}\text { (Rotasyon } \\
\text { Stabilitesi) } \\
\text { Sol }\end{array}$ & $\begin{array}{c}\text { Genç } \\
\text { Küçük } \\
\text { Midi }\end{array}$ & $\begin{array}{l}, 00 \pm, 00 \\
15 \pm, 55 \\
18+, 40\end{array}$ & $\begin{array}{c}8 \\
14 \\
11\end{array}$ & $\begin{array}{l}24 \\
24 \\
24\end{array}$ & & \\
\hline $\begin{array}{c}\text { FHT } \\
\text { (Rotasyon } \\
\text { Stabilitesi) } \\
\text { Sağ }\end{array}$ & $\begin{array}{c}\text { Yıldız } \\
\text { Genç } \\
\text { Küçük } \\
\text { Midi }\end{array}$ & $\begin{array}{l}2,00 \pm, 00 \\
2,00 \pm, 00 \\
2,00 \pm, 00 \\
2,00 \pm, 00\end{array}$ & $\begin{array}{c}14 \\
8 \\
14 \\
11\end{array}$ & $\begin{array}{l}24 \\
24 \\
24 \\
24\end{array}$ & 0 & 1 \\
\hline $\begin{array}{c}\text { FHT } \\
\text { (Bükme } \\
\text { Kontrol } \\
\text { Testi) }\end{array}$ & $\begin{array}{c}\text { Yıldız } \\
\text { Genç } \\
\text { Küçük } \\
\text { Midi }\end{array}$ & $\begin{array}{l}2,00 \pm, 00 \\
2,00 \pm, 00 \\
2,00 \pm, 00 \\
2,00 \pm, 00\end{array}$ & $\begin{array}{c}14 \\
8 \\
14 \\
11\end{array}$ & $\begin{array}{l}24 \\
24 \\
24 \\
24\end{array}$ & 0 & 1 \\
\hline $\begin{array}{c}\text { FHT } \\
\text { (Gövde } \\
\text { Stabilitesi) } \\
\text { Toplam }\end{array}$ & $\begin{array}{c}\text { Yıldız } \\
\text { Genç } \\
\text { Küçük } \\
\text { Midi }\end{array}$ & $\begin{array}{l}0 \\
0 \\
0 \\
0\end{array}$ & $\begin{array}{c}14 \\
8 \\
14 \\
11\end{array}$ & $\begin{array}{l}24 \\
24 \\
24 \\
24\end{array}$ & 0 & 1 \\
\hline $\begin{array}{c}\text { FHT } \\
\text { (Toplam } \\
\text { Skor) }\end{array}$ & $\begin{array}{c}\text { Yıldız } \\
\text { Genç } \\
\text { Küçük } \\
\text { Midi }\end{array}$ & $\begin{array}{l}14,71 \pm 3 \\
14,50 \pm 3 \\
15,86 \pm 3 \\
15,27 \pm 3\end{array}$ & $\begin{array}{c}14 \\
8 \\
14 \\
11\end{array}$ & $\begin{array}{c}21 \\
19,94 \\
28,07 \\
25,59\end{array}$ & 2,9 & 0,41 \\
\hline$K, U, U=K$ & & $\bar{M}=$ Midi & $Y=$ & & & \\
\hline
\end{tabular}

Tablo 2 voleybolcuların oynadıkları kategorilere göre FHT skorlarının karşılaştırılmasını göstermektedir. Tablo incelendiğinde, voleybol sporcularının FHT skorlarından yüksek adımlama sağ ve tek çizgide hamle toplam skorlarında oynadıkları kategoriler arasında anlamlı bir farklılık tespit edilmiştir $(p<0,05)$. Yüksek adımlama sağ skorlarında çoklu karşılaştırma sonucunda küçük (K) kategoride oynayan voleybolcuların midi (M) kategorisinde oynayan voleybolculardan, tek çizgide hamle toplam skorlarında yine aynı şekilde küçük (K) kategorisinde oynayan voleybolcuların yıldız (Y) kategorisinden oynayan voleybolculardan daha iyi FHT skorlarına sahip oldukları görülmektedir.

\section{Tartışma ve Sonuç}

Bu araştırma, farklı yarışma düzeylerindeki (midi, küçük, yıldız ve genç) kadın voleybolcuların FHT test skorlarını karşılaştırmak amacıyla yapılmıştır. Yapılan istatistiksel analiz sporcuların FHT(Yüksek Adımlama) sağ bacak skorlarında küçük ve midi takımları arasında küçük takım lehine ve FHT(Tek Hamlede Çökme) skorlarında küçük ve yıldız takımları arasında küçük takım lehine anlamlı bir fark tespit edilmesine rağmen $(p<0.05)$ çalışmanın diğer değişkenlerinde istatistiksel olarak anlamlı bir fark bulunmamıştır. Ayrıca sporcularda yaralanma intimali ile ilgili bilgi veren FHT(Toplam Skorunun) her kategorideki sporcularda kritik sınır olarak 
Altundağ E, Aka H, İbiş S, Akarçeşme C, Kurt S., (2019). Farklı Yarışma Düzeylerindeki Kadın Voleybolcuların Fonksiyonel Hareket Taraması Test Skorlarının Karşılaştırılması. Gaziantep Üniversitesi Spor Bilimleri Dergisi, 4(3), 319329.

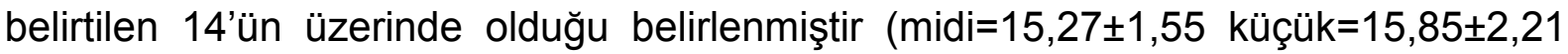
yıldız=14,71 $\pm 1,26$ genç=14,5 $\pm 1,69)$.

Yıldız (2018) yaptığı bir araştırmada 16 yaş ortalamasına sahip 32 karete sporcusunun FHT(toplam skorunu), 15,87 olarak belirlemiştir. Hokey oyuncularına yönelik olarak yapılan bir araştırmada 17.8 yaş ortalamasına sahip olan sporcuların FHT(toplam skoru) 15.2 olarak tespit edilmiştir (Rowan ve ark., 2015). Bir başka çalışmada 8 ve 14 yaş aralığındaki erkek sporcuların FHT(toplam skor) ortalaması 15,2 olarak ölçülmüştür (Paskewicz ve ark., 2012).

Araştırmamızda tek hamlede çökme hareketinde Küçük ve Yıldız takımlar lehine pozitif yönde anlamlı bir fark belirlenmiştir. Bu hareketin sporcuların ani yön değiştirebilmesi ve yavaşlaması esnasında etkili olduğu bilinmektedir (Kiesel ve ark., 2007). Dolayısıyla küçük ve yıldız takım sporcularının yön değiştirme ve yavaşlama becerilerinin daha gelişmiş olduğu düşünülebilir.

FHT(yüksek adımlama) (sağ bacak) alt testinde küçük ve midi takım sporcularının sonuçlarında pozitif yönde anlamlılık belirlenmiştir. Aka ve ark (2018) kadın voleybol milli takımları üzerine yapılan araştırmalarında Türkiye kadın milli takımı sporcularının FHT(yüksek adımlama) test sonuçları çalışmamızı destekler nitelikte olup, diğer takımlardan daha yüksek olarak belirlenmişlerdir. Yüksek adımlama testinde sporcunun bir bacağının stabilitesi gerekirken diğer bacak mobilite durumda olması gerekmektedir. Ayrıca bu harekette kalça fleksiyonunun (Kiesel ve ark., 2007) yansıra vücut ağırlığını bir ayaktan diğerine aktarma esnasında ve denge becerisinde önemlidir (Cook, 2003). Buradan hareketle küçük ve midi takım sporcularının denge gerektiren hareketleri daha etkili bir şekilde yapabildiği ve sıçrama gibi kalça fleksiyonunun önemli olduğu hareketlerde de daha başarılı olabileceği düşünülebilir.

Araştırma grubunda yer alan voleybolcuların FHT(toplam skorları) kritik sınır olarak kabul edilen 14 puandan yüksek olması sporcular için avantajlı bir durum olarak yorumlanabilir. Ayrıca sporcuların fonksiyonel hareket kalıplarındaki eksiklikleri ve hareketlerdeki asimetriler küçük yaşlarda tespit edilmesi önemli olabilir. Sporcuların branşları dikkate alınarak hazırlanan programlar sayesinde fonksiyonel yeterliliğe ulaşılması sağlanabilir (Cowen, 2010). 
Altundağ E, Aka H, İbiş S, Akarçeşme C, Kurt S., (2019). Farklı Yarışma Düzeylerindeki Kadın Voleybolcuların Fonksiyonel Hareket Taraması Test Skorlarının Karşılaştırılması. Gaziantep Üniversitesi Spor Bilimleri Dergisi, 4(3), 319329.

Nitekim literatürde yer alan bazı araştırmalarda voleybolculara uygulanan stabilizasyon ve düzeltici egzersizler sonucunda FHT(toplam skorları) ve fonksiyonel yeterlilikte gelişmeler sağlanmıştır (Linek ve ark., 2016; Aktuğ ve ark., 2019).

Sonuç olarak, voleybolcuların fonksiyonel hareket becerilerinin yarışma düzeyi ile ilişkili olmadığı tespit edilmiştir. Bunun sebebinin katıımcı grupların benzer antrenman düzeyine ve birbirine yakın hareket kabiliyetine sahip olmalarından kaynaklandığı düşünülmektedir. Sporcuların fonksiyonel hareket kalıplarının, antrenmanlarında fonksiyonel hareketleri geliştirici egzersizlerle geliştirilebileceği düşünülmektedir.

Sporcuların fonksiyonel hareketlerinin geliştirilmesi alt yapı eğitiminin içinde yer alarak küçük yaşlarda başlayıp doğru hareket kalıplarıyla birlikte gelişiminin sağlanması önerilebilir. Ayrıca alt yapı antrenörlerinin ve sporcularının fonksiyonel hareketler konusunda bilinçlendirilmesi sağlanarak yapılan antrenmanlarda fonksiyonel hareketleri geliştirici egzersizlere de yer vermeleri sağlanabilir.

\section{Kaynaklar}

Aka, H., Yilmaz, G., Aktug, Z. B., Akarçesme, C., Altundag, E. (2019). The comparison of the functional movement screen test results of volleyball national team players in different countries. Journal of Education and Learning, 8(1): 138-142.

Aktuğ, Z.B., Aka, H., Akarçeşme, C., Çelebi, MM., Altundağ, E. (2019) Elit kadın voleybolcularda düzeltici egzersizlerin fonksiyonel hareket taraması test sonuçlarına etkisinin incelenmesi. Spor Hekimliği Dergisi, 54(10): 1-9.

Cholewicki, J., Silfies, S.P., Shah, R.A., Greene, H.S., Reeves, N.P., Alvi, K., Goldberg, B. (2005). Delayed trunk muscle reflex responses increase the risk of low back injuries. Spine, 30(23): 2614-2620.

Chorba, R. S., Chorba, D.J., Bouillon, L.E., Overmyer, C.A., Landis, J.A. (2010). Use of a functional movement screening tool to determine injury risk in female collegiate athletes. North American Journal of Sports Physical Therapy, 5(2): 47-54.

Cook, G. (2003). Athletic body in balance. Human Kinetics. ISBN: 9781492583776

Cook, G., Burton, L., Hoogenboom, B. (2006). Pre-participation screening: The use of fundamental movements as an assessment of function-part 1. North American Journal of Sports Physical Therapy, 1(2): 62-71 
Altundağ E, Aka H, İbiş S, Akarçeşme C, Kurt S., (2019). Farklı Yarışma Düzeylerindeki Kadın Voleybolcuların Fonksiyonel Hareket Taraması Test Skorlarının Karşılaştırılması. Gaziantep Üniversitesi Spor Bilimleri Dergisi, 4(3), 319329.

Cook, G., Burton, L., Kiesel, K., Bryant, M., Torine, J. (2010). Movement: functional movement systems: Screening, assessment, and corrective strategies: On Target publications aptos, CA.

Cowen, V. S. (2010). Functional fitness improvements after a worksite-based yoga initiative. Journal of bodywork and movement therapies, 14(1): 50-54.

Ergun, N., Baltacı, G. (2006). Spor Yaralanmalarında Fizyoterapi ve Rehabilitasyon Prensipleri. Ankara: Hacettepe Üniversitesi Fizik Tedavi ve Yüksekokulu Yayınları.

Güzel, N., Kafa, N. (2017). Sporcu Sağlığı. Ankara: Sözkesen Matbaacılık.

Kiesel, K., Plisky, P.J., Voight, M.L. (2007). Can serious injury in professional football be predicted by a preseason functional movement screen? North American Journal of Sports Physical Therapy, 2(3): 147-158.

Kraemer, W.J., French, D.N., Paxton, N.J., Hakkinen, K., Volek, J.S., Sebastianelli, W.J., Putukian, M., Newton, R.U., Rubin, M.R., Gomez, A.L., Vescovi, J.D., Ratmess, N.A., Fleck, S.J., Lynch, J.M., Knutgen, H.G. (2004). Changes in exercise performance and hormonal concentrations over a big ten soccer season in starters and nonstarters. Journal of Strength \& Conditioning Research, 18(1): 121-128.

Linek, P., Saulicz, E., Myśliwiec, A., Wójtowicz, M., Wolny, T. (2016). The effect of specific sling exercises on the functional movement screen score in adolescent volleyball players: a preliminary study. Journal of Human Kinetics, 54(1): 83-90.

Marwan, Y., Behbehani A. Al-Mousawi A. Mulla-Juma'a A., Sadeq H., Shah N. (2012). Sports injuries among professional male athletes in kuwait: Prevalence and Associated Factors. Medical Principles Practise, 21(2): 171-177.

Mens, J. M. A., Vleeming, A., Snijders, C. J., Stam, H. J., Ginai, A. Z. (1999). The active straight leg raising test and mobility of the pelvic joints. European Spine Journal, 8(6): 468-473.

Minick, K. I., Kiesel, K. B., Burton, L. E. E., Taylor, A., Plisky, P., Butler, R. J. (2010). Interrater reliability of the functional movement screen. The Journal of Strength \& Conditioning Research, 24(2): 479-486.

Narducci, E., Waltz, A., Gorski, K., Leppla, L., Donaldson, M. (2011). The clinical utility of functional performance tests within one-year post-acl reconstruction: $A$ 
Altundağ E, Aka H, İbiş S, Akarçeşme C, Kurt S., (2019). Farklı Yarışma Düzeylerindeki Kadın Voleybolcuların Fonksiyonel Hareket Taraması Test Skorlarının Karşılaştırılması. Gaziantep Üniversitesi Spor Bilimleri Dergisi, 4(3), 319329.

systematic review. International Journal of Sports Physical Therapy, 6(4): 333342.

Paszkewicz, J.R., McCarty, C.W., Van Lunen, B.L. (2013). Comparison of functional and static evaluation tools among adolescent athletes, Journal Strenght \& Condition Research, 27(10): 2842-2850.

Perry, F., Koehle, M. (2012). Normative Data For The Functional Movement Screen İn Middle-Aged Adults, The Journal of Strength \& Conditioning Research, 27(2): 458-62.

Rowan, C.P., Kuropkat, C., Gumieniak, R..J., Gledhill, N., Jamnik, V. (2015). Integration of the functional movement screen into the national hockey league combine, Journal of Strength \& Conditioning Research, 29(5): 1163-1171.

Solgard, L., Buhl, Nielsen, A., Mdler-Madsen, B., Wulff Ja- cobsen B., Yde, J., Jensen, J. (1995). Volleyball injuries presenting in casualty. A prospective study. British Journal of Sports Medicine, 29(3): 200-204.

Yıldız, S. (2018). Relationship between Functional Movement Screen and Some Athletic Abilities in Karate Athletes. Journal of Education \& Training Studies, 6(8): 66-69. 